\title{
The Diplomatic Burden of Pandemics: The Case of Malaria
}

\author{
Benjamin E. Bagozzi* and Ore Koren ${ }^{\dagger}$
}

March 17, 2020

\begin{abstract}
The social and economic burdens of pandemics are becoming increasingly well-known. This paper seeks to gain a better understanding of this phenomena by assessing one highly prevalent global pandemic: malaria. It does so by evaluating malaria's burden on the political ties of nation-states, and on international relations more generally. We posit that malaria dissuades foreign countries from locating their envoys in malaria-affected states. As a consequence, a protracted pandemic has the potential to undermine the political ties of nation-states, as well as the many benefits of these connections. This argument is tested empirically using both directeddyadic and monadic data. We find that malaria not only serves to discourage foreign governments from establishing diplomatic outposts, but also decreases the total diplomatic missions that a country receives. These findings thus have important policy implications, especially for developing states that seek to increase their global political impact while simultaneously combating persistent pandemics.
\end{abstract}

\footnotetext{
*Department of Political Science \& IR. University of Delaware. Email: bagoz zib@udel . edu.
}

${ }^{\dagger}$ Department of Political Science, Indiana University Bloomington. Email: okoren@iu . edu. 
"Decline in public health programs in some Third World nations poses new dangers to diplomats and their families. Of special concern to Dr. Martin Wolfe, State's senior specialist in tropical diseases, is the emergence of drug-resistant malaria in parts of Africa and Asia."

- The Washington Post, 1984

"What you are paid more for is half the family coming down with malaria...My wife has had it. My boys have had it."

\section{- Francis S. Rudy, Former American Ambassador to Equatorial Guinea}

Can pandemics have long-term global political implications? Pandemics are not just sudden outbreaks of disease; they are epidemics that affect wide geographic areas and impact the lives of hundreds of thousands if not millions of individuals (see, e.g., WHO 2015; Hatchett, Mecher and Lipsitch, 2007). ${ }^{1}$ Unsurprisingly, then, in recent years, social scientists have become increasingly aware of the economic and social burdens of pandemics. It is not hard to see why. The last Ebola outbreak in western Africa, for instance, "had a devastating impact on the economies of Guinea, Liberia and Sierra Leone...the economy has deflated by 30\%."2 Focusing on malaria, Sachs and Malaney $(2002,682)$ find that it adversely impacts household behaviors in anything from schooling, through demography and migration, to financial savings, which in turn leads to broader social costs. Indeed, the evidence that malarial countries experience consistently higher levels of poverty and lower levels of economic development compared to non-malarial states is formidable (e.g., Gallup and Sachs, 2001; Sachs and Malaney, 2002).

Interestingly, despite the attention given to the socioeconomic effects of pandemics, relatively little attention has been given to their international political implications. ${ }^{3}$ This is puzzling given their documented developmental and economic impacts. While the potential channels by which pandemics might impact politics are plentiful, we focus on one particular form of international political interaction with significant implications for other areas of domestic and international politics: diplomatic missions. In this context, diplomatic missions are

\footnotetext{
${ }^{1}$ Accordingly, the empirical measures used below employ a geospatial component for operationalization.

${ }^{2}$ ThisIsSierraLeone, "Ebola Crisis: The Economic Impact," accessed October 23, 2019. http://www. thisissierraleone.com/ebola-crisis-the-economic-impact/.

${ }^{3}$ For a notable exception, see Enemark (2017).
} 
defined as the formal existence of diplomatic relations between countries at the level of chargè d'affaires, minister, or ambassador (Singer and Small, 1973). These forms of political relations have proven to be one of the most enduring forms of international political linkages between nation states, and remain a primary tool for international negotiation, cooperation, trade promotion, dispute settlement, foreign intelligence management, and cultural exchange in modern times (Rose, 2007; Neumayer, 2008; Bagozzi and Landis, 2015).

Diplomatic missions hence provide a highly effective, deeply historical form of international relations on which to evaluate pandemics' effects. Indeed, a great deal of case-specific and empirical evidence also suggests that the sending and receiving of diplomatic missions is shaped not only by national interests, but also by concerns over the wellbeing of those who must occupy these missions' embassies and consulates abroad-i.e., diplomats and their families, foreign service support staff members, and other security or intelligence operatives-and specifically health wellbeing. Extant findings suggest that transnational political actors have been able to consistently steer foreign assignments and diplomatic mission-locations to countries that offer a higher quality of life, and fewer human security threats, for foreign service members and their families (Neumayer, 2008; Rose, 2007, 27-32; fn 21).

While there are several diseases that could cause said impacts-including, e.g., malaria, tuberculosis (TB), Ebola, and influenza - in this study we chose to focus on malaria, for four main reasons. Firstly, malaria has a deep historical impact on international relations and international development in modern times, going back to at least the construction of the Panama Canal, when it shaped the stakes of the states involved and their investment in the project (McCullough, 1977; Gallup and Sachs, 2001, 88). Second, unlike epidemics that are characterized by outbreak followed by remission—as is the case for influenza (e.g., Peasah et al., 2013; Nicholson, 1992) and Ebola (Park et al., 2015)—malaria is persistent, namely, it is always present, effecting millions of individuals worldwide (Sachs and Malaney, 2002,WHO 2015). Third, malaria is extremely deadly — according to its 2015 report, the $\operatorname{WHO}(2015,4)$ estimates that the parasite killed a staggering 584,000 people, on average, in 2013 alone. Finally, malaria is globally prevalent and impacts more individuals than most of its contemporaries-again, the WHO $(2015,4)$ estimates that 198 million cases occurred in 2013, compared to approximately 
8.6 million who experienced TB. We hence believe malaria prevalence provides an important test case for evaluating whether and the extent to which pandemics affect diplomatic missions.

Building on these issues, we argue that foreign service members' perceptions of malaria prevalence in potential diplomatic host countries will compel these actors to steer their diplomatic missions to more agreeable regions, hence affecting international relations between the two states. Indeed, as alluded to above, extant malaria research provides sound theoretical evidence that international actors make these types of decisions-and avoid malarial countrieswhen engaging in other forms of international activity, including in trade, tourism, and foreign direct investment (Sachs and Malaney, 2002). Similarly, a great deal of case-specific evidence and individual accounts (summarized below) also imply that perceived malaria risks, for both individuals and their families, are a pressing concern for diplomatic service members when weighing the costs and benefits of a given diplomatic assignment. Because countries' foreign service departments typically wield a great deal of influence in directing, and assigning, foreign missions to particular host countries, these concerns 'trickle-up' to the foreign policy decisionmaking level, and compel national governments to be less likely to assign, and establish, formal diplomatic relations with countries whose malaria rates are perceived to be a serious threat to a government's diplomatic corps.

To test this argument empirically, we evaluate (i) whether countries are less likely to establish diplomatic missions with other countries when the latter countries' malaria rates are high and (ii) whether individual countries receive lower numbers of diplomatic missions in total as their individual malaria rates increase. For this purpose we employ both dyadic and monadic datasets measuring diplomatic missions activity and malaria prevalence over the 1950-2005 period, accounting for a large number of confounders. In support of our contentions, we find that higher rates of malaria significantly and substantively reduce the likelihoods of both directed dyadic diplomacy and total diplomatic missions received. These results are robust to the inclusion of numerous controls for economic development, democracy, education system quality, geography, and political instability, as well as endogeneity and serial correlation concerns. Indeed, malaria's negative effects in both samples is larger or comparable to those of many other commonly identified determinants of diplomatic linkages, such as interstate proximity 
and geographic remoteness.

Our ultimate conclusion is hence that malaria prevalence, and the ubiquity of pandemics more broadly, places a high burden on the modern political ties of nation states. These findings contribute to the extant body of work relating to the social burdens of epidemiological factors (Gallup and Sachs, 2001; Sachs and Malaney, 2002; Letendre, Fincher and Thornhill, 2010; Bagozzi, 2016), and have important implications for our understandings of how pandemics shape both the political-economic interactions of transnational actors and the broader international relations of nation-states. More specifically, in parallel to the argument that, "[t]hroughout history, malaria has suppressed the economic linkages between malarious and non-malarious regions" (Sachs and Malaney, 2002, 684), our findings show malaria has had a comparable effect on the political linkages between malarious and non-malarious states.

Considering climate trends, the prevalence of pandemics due to both known and yet-to-beencountered pathogens is likely to rise (GPMB 2019). Our findings hence not only suggest that the role of pandemics in international relations would benefit from dedicated scholarship to uncover pathways by which different pathogens impact global stability; they also highlight that pandemics' role(s) in shaping such relations should be taken seriously by policymakers. We discuss these implications in greater detail in the conclusion.

We proceed as follows. In the first section we delineate our theoretical expectations regarding the factors that shape diplomatic missions more broadly. We then proceed to discuss how pandemic/malaria prevalence relates to such impacts, and derive testable hypotheses. The ensuing section then discusses the data, methods, and results of the dyadic data analysis used to evaluate the probability a given sender state establishes a mission in a given host state. The third section then does the same with respect to the total number of missions in a given country. The fourth section then accounts for the possibility of endogeneity and serial correlation in our results. We conclude with some research and policymaking implications of our findings. 


\section{Diplomacy and Malaria: A Theory}

\section{Factors shaping diplomatic missions}

The practice of establishing diplomatic relations with foreign polities predates the inception of the modern nation-state. Historically, such missions served as central means for governments to conduct their international relations, promote their economic interests, and maintain their power and prestige abroad. ${ }^{4}$ Post-World War II (WWII), these traditional roles of diplomatic missions have expanded further to aid states in directing their foreign security policy when foreign intra and interstate wars arise (Rosati and Scott, 2010, 138) and communicating with and aiding citizens abroad during natural disasters and related emergencies (Haywood and Majerus, 2014, 2). In the current era of state-to-state relations, diplomatic missions continue to function as an essential policy instrument in these regards (Bagozzi and Landis, 2015, 18).

Scholars have widely argued that embassies and diplomatic ties have come to play an increasingly pivotal role in the promotion of states' economic interests abroad, and have found such ties to be robustly related to increased trade flows (Rose, 2007; Segura-Cayuela and Vilarrubia, 2008) and reduced trade volatility (Bagozzi and Landis, 2015). In the United States, for instance, contemporary politics has mirrored this trend, with the Obama administration announcing in late 2013 an "overseas economic strategy that would judge ambassadors on the amount of foreign direct investment they brought in, on top of the American exports they enabled." ${ }^{5}$ Given these trends, state-to-state diplomacy remains critical to countries' economic and political standings in what is becoming an increasingly globalized world.

Case-based evidence suggests that, often, the decision if and where to establish local relations is shaped not (only) by senior policymakers, but also by rank-and-file members of countries' respective diplomatic corps. In the U.S. for example, the State Department frequently lobbies its own government for the establishment of formal diplomatic ties with foreign states, and embassies therein. This was the case, for instance, with respect to Macedonia in the 1990's, wherein the U.S. State Department domestically "stressed its belief that establishing diplomatic

\footnotetext{
${ }^{4}$ In this vein, historical accounts argue that diplomacy directly allows states to avoid war with one another (e.g., Beilenson, 1980; Bennett, 2006, 67; 393), and accordingly attribute the outbreak of war to failures of diplomacy (e.g., Dorman and Kennedy, 2008, 183).

${ }^{5}$ Lydia Depillis, “Do Ambassadors Matter?” The Washington Post December 24, 2013.
} 
relations between the two countries would 'help to strengthen the stability of the region"' (Shea, 1997, 360). ${ }^{6}$ In other cases the U.S. State Department's Secretary has played an even more instrumental role in establishing diplomatic relations with states and spearheading the creation of embassies by, in one such instance of policy gridlock, " "making the decision to cut through the bureaucratic fog on both sides' [... and moving] forward with plans to establish an embassy" (Addleton, 2013, 30-31). ${ }^{7}$

Moreover, while executives and congressional bodies do play a role in these approval processes - and especially so for key states related to a country's national interest-evidence suggests that such actors shy away from micromanaging these decisions when national interests are not of immediate concern. For example, the U.S. Congressional record indicates one House of Representatives member as stating in this regard that, "I cannot think of a dumber thing that we could do as to take this money away and to try and micromanage the way that we are going to establish an embassy..." (Congressional Record-House, 2005). This casebased evidence, in addition to research discussed below, suggest that diplomats have both the incentives and abilities to lobby their government to opt for-or against—locating a diplomatic mission within a given country, including in pandemic-affected states.

Though politically and economically beneficial, governments' use of diplomatic missions and envoys costs scarce resources, which can pose a strong constraint on developing or smaller states. Accordingly, scholars note a high degree of variance in the number (and extent) of diplomatic ties across countries and time (Neumayer, 2008). States (and diplomats) must make choices in where to send their limited diplomatic resources, and that in this endeavor, one typically sees governments weighing cost-benefit calculations when choosing diplomatic destinations (Neumayer, 2008; Kinne, 2014). In particular, factors such as proximity, power, and ideological affinity weigh heavily on governments' perceptions of a potential diplomatic mission's benefits, as these criteria, when present, ensure that the perks of diplomatic missions, including those related to trade promotion, cultural exchange, economic cooperation, and di-

\footnotetext{
${ }^{6}$ Historically, similar dynamics have arisen in efforts to initially establish permanent diplomatic relations between nation-states. For instance, the establishment of permanent British-Chinese relations in 1834 where impeded when Britain's diplomatic representative and his translator both contracted Malaria in China and passed away (Kissinger, 2011).

${ }^{7}$ Comparably autonomous decision-making has been evident in the Canadian Secretary of State's direction of embassy locations in Africa (Gendron, 2006).
} 
rect lines of access to allies and major powers, will be maximized (Neumayer, 2008; Rose, 2007).

In addition to establishment, the upkeep of diplomatic missions is also potentially costly for states with respect to both their national interests and bureaucratic maintenance. Regarding the former, careful political considerations must be made by leaders in their assignment of diplomatic missions to particular states (and diplomatic recognition thereof) given the backlash that controversial diplomatic relations can provoke among domestic actors and allied states (Neumayer, 2008; Kinne, 2014). As for the latter, a country's foreign service department's operating budget, and its diplomatic service members themselves, can often incur variable service costs depending on an intended diplomatic host country's social, political, and economic environment. Indeed, as one longtime Canadian foreign service member observed in this regard, ${ }^{8}$ “[y]ou don't enjoy every minute of life when you're in a country that, after a while, you find difficult to live in, where the cultural differences affect the role of women, where children have to live in a compound and can't go on the street, where malaria is a fact of life". 9

Due to these perceived costs, diplomats and their support staffs often lobby, direct, or guide foreign policy decision-making so as to ensure that diplomatic missions are established and located in relatively agreeable locals. For instance, Neumayer $(2008,231)$ observes that geographic proximity lowers the costs of diplomatic representation in that it "is cheaper to set up and maintain embassies in close countries and easier to persuade staff to move to such countries, where the climate and culture is similar and home, with all its amenities (food, media, schools for the children, etc.), is not far away." Similarly, Rose (2007) empirically confirms that the individual preferences of diplomatic corps-including the perceived (un)desirability of a potential host country—often influence the actual location of diplomatic missions sent abroad.

\footnotetext{
${ }^{8} \mathrm{An}$ account from the U.S. perspective similarly characterized the U.S. foreign service as one where "[p]olluted drinking water, severe pollution, malaria and other diseases are facts of life in dozens of overseas posts. Constant security threats in countries such Colombia, Haiti and Liberia and in areas such as the Middle East, make living conditions even harder." Ups and Downs of Diplomacy; Americans Weigh Risks, Rewards. Nicholas Kralev. The Washington Times. April 19, 2004.

${ }^{9}$ Laura Pratt, "They Joined the Foreign Service to See the World But..." The Financial Post November 1, 1995.
} 


\section{Malaria as a determinant of diplomacy}

Building on these insights, we argue that a potential diplomatic host country's levels of pandemic prevalence-specifically malaria-will make governments to be less likely to establish diplomatic relations. As discussed above, factors such as cultural (dis)similarity, distance, health threats, and the (un)availability of shopping, schooling, and housing amenities can each exert a strong influence on diplomatic service members' incentives to serve in some countries and not others. Moreover, the costs of adjusting to life in such countries become higher in the presence of such challenges. Associated concerns will often accordingly alter the actual locations (and establishments) of embassies and consulates (Rose, 2007; Neumayer, 2008).

Like these factors, pandemics—including malaria—can affect the diplomatic staff's standardsof-living and directly endanger their health. Additionally, the costs of preventing and mitigating such pandemics can be high due to a variety of factors, ranging from vaccinations and treatments, through hospitalization, to the number of workdays lost due to indisposed staff and their family members (WHO 2015; Sawyer, 1993; Sachs and Malaney, 2002). Although these costs can be absorbed relatively easily by wealthier states such as the U.S., they can be prohibitive to many poorer and smaller states. Facing opportunity costs of where to invest their more limited pool of resources, such countries will steer diplomatic relations away from highly pandemicand specifically, highly malarial countries_-and towards more inviting locales.

Focusing on malaria, extant research suggests that incidence and prevalence rates do indeed have the capacity to shape the decisions and actions of transnational actors, often compelling these actors to choose against undertaking activities in malarial countries when alternative locations are available. One example is that of international trade and foreign direct investment, which are adversely affected by the presence of malaria for the very reasons discussed above. For instance, Sachs and Malaney $(2002,684)$ find that as "incentives to expand markets into malarious regions of the world will be lost in the event that trade and commercialization expose people to an increased burden of malaria...investors from non-malarious regions tend to shun malarious regions for fear of contracting the disease - a fear that is sadly well grounded in reality." Similar contentions have also been leveraged with respect to malaria's adverse effects on tourism. (Gallup and Sachs, 2001, 95), for example, find that "[m]alaria, unlike diseases re- 
sulting from poverty, does not discriminate between rich and poor victims. As long as malaria protection is imperfect and cumbersome, well-to-do foreign investors and tourists may stay away from malarial countries." (Gallup and Sachs, 2001, 95).

These contentions suggest that a variety of transnational actors, ranging from foreign investors and businessmen to tourists, will consciously avoid malarial regions-provided that other opportunities exist. Accordingly, we argue that diplomats and diplomatic missions are shaped in a comparable fashion. All else equal, services will be avoided in, or withdrawn from, states and regions where malaria is ubiquitous, and will instead be directed toward countries where this risk is lower whenever possible.

This claim is supported by ample case-specific evidence, which implies that diplomatic actors do in fact make these sorts of cost-benefit calculations with respect to malaria. For example, a 1984 Washington Post account of U.S. Diplomatic and State Department woes noted that a "decline in public health programs in some Third World nations poses new dangers to diplomats and their families. Of special concern to Dr. Martin Wolfe, State's senior specialist in tropical diseases, is the emergence of drug-resistant malaria in parts of Africa and Asia."10 Indeed, even in an era of severe Cold War tensions, news reports depict malaria as being on the forefront of State Department security and health concerns. Similarly, the U.S. Ambassador to Equatorial Guinea, in discussing the U.S. embassy's potential closure in that country, likewise lamented that " $[\mathrm{w}]$ hat you are paid more for is half the family coming down with malaria [...] My wife has had it. My boys have had it."11

These concerns are not unique to U.S. diplomatic missions. The Canadian press similarly reported concerns voiced by an anonymous ambassador to Equatorial Guinea noted that "malaria is nearly a certainty, despite precautions". ${ }^{2}$ Likewise, Britain's Ambassador to the U.S. during World War I—Sir Cecil Spring Rice—notably requested a move from "the semitropical climate of Washington" due to his belief that the hot and humid weather of Washington, D.C. posed a danger to his health given a previous bout with malaria-a request that was received favorably by the British Foreign Office (Burton, 1990, 31). Comparable concerns over

\footnotetext{
${ }^{10}$ Don Oberdorfer, "State Department; Foggy Bottom Ups, Downs," The Washington Post December 27, 1984

${ }^{11}$ James Brooke, "U.S. Outpost Feels Threat Of Budget Ax," The New York Times October 27, 1987.

${ }^{12}$ Oakland Ross, "West African Nation Shaking off Image as Worst Posting for Envoys," The Globe and Mail (Canada) June 15, 1989.
} 
the harm done by malaria to foreign service operations have been echoed more recently in media accounts of senior diplomatic representatives originating from countries ranging from Australia to Singapore. ${ }^{13}$ These individual accounts hence clearly suggest that malaria has been a paramount concern among members of the foreign services throughout much of the modern era.

Building on both the extant literature and case-based evidence discussed in this section, we argue that the prevalence and persistence of pandemics shape governments' decisions on whether or not to send a diplomatic mission to a given state. Stated empirically and applied to the case of malaria - the focus of our analysis—-this leads to the following hypothesis:

- H1: A country will be less likely to establish a diplomatic mission on another country's soil as the latter country's malaria rate increases

A logical extension of $\mathrm{H} 1$ is that if the likelihood of any given country establishing a diplomatic mission decreases in the host country's malaria rates, then the total number of diplomatic missions in this country should also increase. This suggests the following:

- H2: The number of diplomatic missions in host countries will decrease with higher malaria rates

\section{Dyadic Data Tests of Hypothesis 1}

Data, Variables, Methods

H1 assumes that in interactions between two states $i$ (sender) and $j$ (host), diplomatic activity will decrease where malaria rates are high. We accordingly create a data frame where the crosssectional unit of analysis is the directed dyad for all directed pairs of countries $(i$ and $j)$ in the world from 1950-2005. Using this dyadic framework allows us to control not only for sending and receiving country-specific factors, but also for dyad specific confounders when assessing the effects of malaria rates on diplomacy.

\footnotetext{
${ }^{13}$ See, e.g., Ong Soh Chin,"Non-Resident Envoys Keep Singapore Plugged in Globally" The Straits Times June 26, 2007; Anthony Laver and Jillian Stevens, "Man of Many Talents and Achievements," Canberra Times November 22, 2002.
} 


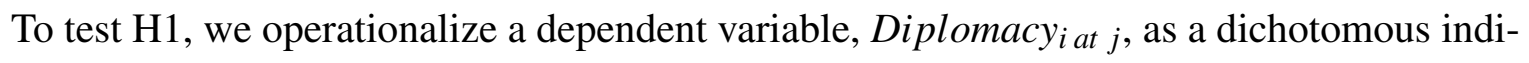
cator of whether $(=1)$ or not $(=0)$ country $y_{i}$ has established formal diplomatic representatione.g., a chargè d'affaires, minister, or ambassador-within country ${ }_{j}$ 's territory during a given time period. Information for creating this variable was obtained from the Correlates of War's (COW) Diplomatic Exchange dataset (Bayer, 2006). Due to the slow moving nature of diplomatic ties, this dataset was only measured at 5 year intervals, and hence our temporal unit of analysis corresponds to these half-decade (i.e., 5-year) periods. ${ }^{14}$ This temporal framework thus provides us with (up to) 11 periods per dyad for our final 1950-2005 panel dataset. Summary statistics for this dependent variable, as well as for all of the independent and control variables described below and in all robustness models, appear in Table A1, Supplemental Appendix.

To test the impact of malaria on our department variable, we utilize the average malaria prevalence at the host country, Malaria Prevelance ${ }_{j}$, similarly measured at 5-year intervals in three steps. First, data on the percentage of host country, country $y_{j}$ 's land area with malaria exposure in the years 1946, 1966, 1982, and 1994 were obtained from the Center for International Development (CID) Malaria data set (Gallup, Mellinger and Sachs, 2001), and interpolated to the yearly level. ${ }^{15}$ Next, we use the proportion of a country's land area with malaria, rather than the proportion of a country's population living in malarial regions, because the former data best reflect the information available to diplomatics for every year during the 1950-2005 time period. Indeed, while the CID's population-based malaria measures are reported for the same time intervals mentioned above (i.e., 1946, 1966, 1982, 1994), they were not calculated and made publicly available until the late 1990s and were constructed, in each case, using geographic population projections for the year 1995. Hence, these population based measures correspond poorly with diplomats' real-time assessments of potential malaria rates abroad, relative to the geographic malaria prevalence data available to them during the 1950-2005 time period through World Health Organization reports-from which the geographic malaria rates data used here are drawn. We demonstrate robustness to a population-based malaria measure in Table A5, Supplemental Appendix. Finally, to account for the time it takes for diplomats

\footnotetext{
${ }^{14}$ For robustness, we present a comparable set of yearly models, with interpolated values on Diplomacy $y_{\text {a }} j$, in Table A2, Supplemental Appendix to show our results are unaffected by the reliance on different temporal units.

${ }^{15}$ E.g., country-years prior to 1957 were assigned a country's CID recorded malaria rate in 1946, whereas country years between 1957 and 1966 were assigned that country’s 1966 CID malaria rate, and so on.
} 
to learn of malaria prevalence, we lag this variable by one (5-year) time period. The resultant Malaria Prevelance $j$ variable ranges from 0 to 1 , with a sample mean of 0.45 , and roughly $60 \%$ of all observations taking on either a value of 0 (38\% of observations) or 1 ( $25 \%$ of observations).

Considering the number of factors that might confound our main explanatory variables effects, our models also include a large number of controls. First, note that Neumayer (2008, 234) provides one the most comprehensive quantitative assessment of the determinants of (directed) diplomatic representation to date. We therefore draw on his identified correlates when specifying our own set of control variables. Accordingly, we first include controls for dyadic distance, Distance $_{i j}$; material capabilities to account for both the sending $\left(C I N C_{i}\right)$ and host $\left(C I N C_{i}\right)$ states' capacity; a variable measuring closeness of ideology between both countries in the dyad, Ideology $y_{i j}$; an interaction term between ideological affinity and material capacity for both sending country $\left(C I N C_{i} \times I\right.$ Ideology $\left.y_{i j}\right)$ and host country $\left.\left(C I N C_{j} \times I_{\text {deology }}\right)_{i j}\right)$; whether there was a history of colonial relations between two states, Colony Ties $i j$; the level of democracy in sending $\left(\right.$ Democracy $\left._{i}\right)$ and host country $\left(\right.$ Democracy $\left._{j}\right)$, as well as the interaction between the two states $\left(\right.$ Democracy $_{i} \times$ Democracy $\left._{j}\right)$. Detailed operationalizations and source material for each covariate are provided in the Supplemental Appendix.

In addition to these diplomatic determinants, we also draw on research into the social effects and causes of malaria to include a number of additional controls. Here, we add a control for each dyad's bilateral $\operatorname{Trade}_{i j}$ flows, since it has been widely argued that malaria inhibits bilateral trade flows between countries (Gallup and Sachs, 2001), while such flows are also strongly tied to directed diplomatic representation (Rose, 2007). We then account for the role of economic development more broadly by including controls for both (xi) sending $\left(G D P p c_{i}\right)$ and host $\left(G D P p c_{j}\right)$ countries' levels of GDP per capita. We also follow past studies on malaria's effects on political-economic outcomes (e.g., Sachs and Malaney, 2002) by controlling for a country's geographic tropical location via a measure of the percentage of a country's landmass that lies in the geographical tropics (\% Tropics $_{j}$ ), also taken from the CID (Gallup, Mellinger and Sachs, 2001). ${ }^{16}$. To account for the role of reciprocal in diplomatic relations, we include a

\footnotetext{
${ }^{16}$ The results are robust to using country $j$ 's (logged) geographic latitude instead
} 
variable controlling for whether or not the host country has a diplomatic mission at the receiving

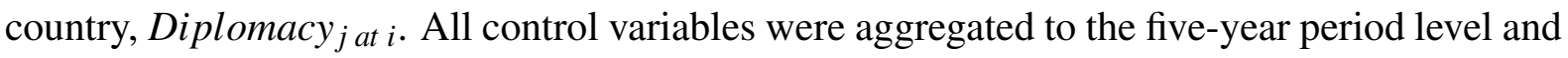
then lagged by one period in a manner consistent to that described for Malaria Prevelance ${ }_{j}$ above. ${ }^{17}$ Finally, to account for period-specific effects, all but the baseline models include time period fixed effects.

Given that our dependent variable, Diplomacy ${ }_{i}$ at $j$, is binary, we employ logistic regression. As our data are panel in nature, we employ different model adjustments to account for the cross-sectional and temporal dependencies of our observations. We hence begin by reporting a baseline logit model that includes only our main explanatory variable, Malaria Prevelance ${ }_{j}$, with no additional controls. We then add to this baseline specification the controls discussed above, along with time-period (i.e., half-decade) fixed effects, to arrive at our second (pooled) logit model. We then estimate a similar model where standard errors are clustered by directed dyad to account for the possibility the information on some observations is heterogeneous over time. Next, we add conditional fixed effects for each directed dyad to isolate malaria's effect on directed diplomatic representation solely within each directed dyad, rather than across dyads. Finally, we reassess our fully specified logit models with directed dyad random effects in place of the cross-sectional fixed effects. ${ }^{18}$ Using this assortment of models ensures our findings are not the result of a large number issues that might affect such panel data.

\section{Results}

Table 1 provides strong evidence in support of hypothesis H1. Most importantly, the coefficient estimate for Malaria Prevelance ${ }_{j}$ is negative and significant $(p<.01)$ in the first column of Table 1. That suggests that absent any controls or panel-data adjustments, increases in host country $j$ 's malaria prevalence reduce its likelihood of receiving a diplomatic mission from a sending country. These results remain robust as more controls are added to arrive at the pooled model (Model 2) and the inclusion of clustered standard errors by dyad (Model 3), as well as dyad fixed and random effects (Models 4 and 5).

\footnotetext{
${ }^{17}$ Our results remain unchanged when non-lagged measures are used instead in Table A3, Supplemental Appendix.

${ }^{18}$ While Hausman tests confirm that the dyad fixed effects models are preferred, this specification omits variables and observations where data is constant over time.
} 
Several of our control variable estimates are also statistically significant in their expected directions in Models 2-3. For instance, more developed and more powerful countries are significantly more likely to send and receive diplomatic missions, whereas potential senders are also more likely to have established diplomatic relations with a potential receiving country when they themselves already host a diplomatic mission from that receiving country. Dyads with colonial and trade ties are also significantly more likely to establish diplomatic relations. Finally, and very interestingly, once the role of malaria prevalence is accounted for, potential receiving countries are more likely to receive a diplomatic mission as their \% Tropics $_{j}$ increases, an effect that is perhaps due to the desirability effects related to travel and tourism, as described in Rose (2007).

To assess the substantive magnitude of malaria's impact on diplomatic relations, we calculate the estimated effects of Malaria Prevelance ${ }_{j}$ on the predicted probability of Diplomacy $_{i}$ at $j=$ 1, along with the $95 \%$ confidence intervals, in Figure 1. These effects were calculated when using the most conservative Malaria Prevelance ${ }_{j}$ estimates above (Model 2) by extracting the predicted probability of Diplomacy $y_{i} j=1$ for each value of Malaria Prevelance ${ }_{j}(0 \rightarrow 1)$, while holding all other variables at their means or modes. As Figure 1 shows, the predicted probability a given sending state $i$ will establish a diplomatic mission in a given host country $j$ across the range of Malaria Prevelance ${ }_{j}$ values decreases by $3.5 \%$, on average. While these effects might not appear very substantive, they are relatively sizable considering our large sample size and the (low) variation in Diplomacy $i_{i} j$. For comparison, a standard deviation increase in either $G D P p c_{j}$ or Distance $_{i j}$ - arguably two of the strongest predictors of diplomatic ties (Neumayer, 2008) — have comparable average predicted effects of approximately $4 \%$ and 7\%, respectively. Hence, eliminating Malaria Prevelance ${ }_{j}$ has a non-negligible substantive effect on a country's likelihood of receiving a diplomatic mission from a potential sending country during a given five year period.

Although the above analysis demonstrates the robustness of our findings across a wide number of control variable specifications and under a variety of panel-data adjustments, we additionally estimate a large number of robustness models in Tables A2-A8, Supplemental Appendix. To this end, we first reproduce our five models with all data aggregated to the yearly 
Table 1: Determinants of Directed Diplomatic Representation, 1950-2005

\begin{tabular}{|c|c|c|c|c|c|}
\hline & Malaria-Only & Pooled & Clustered SEs & Dir-Dyad FEs & Dir-Dyad REs \\
\hline$\overline{\text { Malaria Prevelance }}_{j}$ & $\begin{array}{c}.811 * * * \\
(.012)\end{array}$ & $\begin{array}{c}.170 * * * \\
(.041)\end{array}$ & $\begin{array}{c}-.170 * * \\
(.059)\end{array}$ & $\begin{array}{c}.416 * * * \\
(.093)\end{array}$ & $\begin{array}{c}.230 * * * \\
(.073)\end{array}$ \\
\hline$\%$ Tropics $_{j}$ & . & $\begin{array}{c}.592 * * * \\
(.036)\end{array}$ & $\begin{array}{l}.592 * * * \\
(.054)\end{array}$ & . & $\begin{array}{c}.882 * * * \\
(.081)\end{array}$ \\
\hline Distance $_{i j}{ }^{1}$ & . & $\begin{array}{c}-.849 * * * \\
(.016)\end{array}$ & $\begin{array}{c}-.849 * * * \\
(.026)\end{array}$ & . & $\begin{array}{c}-1.547 * * * \\
(.039)\end{array}$ \\
\hline Dyadic Trade $_{i j}{ }^{1}$ & . & $\begin{array}{c}.205 * * * \\
(.006)\end{array}$ & $\begin{array}{c}.205^{* * * *} \\
(.009)\end{array}$ & $\begin{array}{c}.220 * * * \\
(.014)\end{array}$ & $\begin{array}{c}-.318 * * * \\
(.010)\end{array}$ \\
\hline Colonial Ties $_{i j}{ }^{1}$ & . & $\begin{array}{c}1.869 * * * \\
(.132)\end{array}$ & $\begin{array}{l}1.878 * * * \\
(.215)\end{array}$ & . & $\begin{array}{l}3.286 * * * \\
(.269)\end{array}$ \\
\hline Diplomacy $_{j \text { at } i}{ }^{1}$ & . & $\begin{array}{c}2.318 * * * \\
(.022)\end{array}$ & $\begin{array}{c}2.318 * * * \\
(.032)\end{array}$ & $\begin{array}{c}1.250 * * * \\
(.040)\end{array}$ & $\begin{array}{c}2.343 * * * \\
(.036)\end{array}$ \\
\hline$G D P p c_{j}^{1}$ & . & $\begin{array}{c}.080 * * * \\
(.012)\end{array}$ & $\begin{array}{c}.080 * * * \\
(.019)\end{array}$ & $\begin{array}{c}-.142 * * \\
(.061)\end{array}$ & $\begin{array}{c}.157 * * * \\
(.026)\end{array}$ \\
\hline$G D P p c_{j}^{1}$ & . & $\begin{array}{c}.248 * * * \\
(.016)\end{array}$ & $\begin{array}{c}.248 * * * \\
(.024)\end{array}$ & $\begin{array}{c}.318 * * * \\
(.062)\end{array}$ & $\begin{array}{c}.497 * * * \\
(.033)\end{array}$ \\
\hline Ideology $_{i j}$ & . & $\begin{array}{l}.144 \\
(.184)\end{array}$ & $\begin{array}{l}.144 \\
(.326)\end{array}$ & $\begin{array}{l}4.206 * * * \\
(.521)\end{array}$ & $\begin{array}{c}1.107 * * * \\
(.346)\end{array}$ \\
\hline $\operatorname{CINC}_{i}{ }^{1} \times$ Ideology $_{i j}$ & . & $\begin{array}{c}.107 * * * \\
(.018)\end{array}$ & $\begin{array}{c}.107 * * * \\
(.032)\end{array}$ & $\begin{array}{l}.276^{* * * *} \\
(.053)\end{array}$ & $\begin{array}{c}.143 * * * \\
(.034)\end{array}$ \\
\hline CINC $_{j}{ }^{1} \times$ Ideology $_{i j}$ & . & $\begin{array}{c}-.122 * * * \\
(.019)\end{array}$ & $\begin{array}{c}-.112 * * * \\
(.032)\end{array}$ & $\begin{array}{c}.224 * * * \\
(.054)\end{array}$ & $\begin{array}{l}-.044 \\
(.036)\end{array}$ \\
\hline $\operatorname{CINC}_{i}{ }^{1}$ & . & $\begin{array}{l}.380 * * * \\
(.015)\end{array}$ & $\begin{array}{l}.380 * * * \\
(.026)\end{array}$ & $\begin{array}{l}.552 * * * \\
(.074)\end{array}$ & $\begin{array}{c}.750 * * * \\
(.030)\end{array}$ \\
\hline $\operatorname{CINC}_{j}{ }^{1}$ & . & $\begin{array}{c}.419 * * * \\
(.016)\end{array}$ & $\begin{array}{c}.419 * * * \\
(.027)\end{array}$ & $\begin{array}{l}-.072 \\
(.075)\end{array}$ & $\begin{array}{c}.700 * * * \\
(.033)\end{array}$ \\
\hline Democracy $_{i} *$ Democracy $_{j}$ & . & $\begin{array}{c}.433^{* * *} \\
(.044)\end{array}$ & $\begin{array}{c}.433^{* * * *} \\
(.061)\end{array}$ & $\begin{array}{c}-.437 * * * \\
(.092)\end{array}$ & $\begin{array}{l}.063 \\
(.074)\end{array}$ \\
\hline Democracy $_{i}$ & . & $\begin{array}{l}.274 * * * \\
(.031)\end{array}$ & $\begin{array}{l}.274 * * * \\
(.044)\end{array}$ & $\begin{array}{l}.263 * * * \\
(.075)\end{array}$ & $\begin{array}{l}.421 * * * \\
(.057)\end{array}$ \\
\hline Democracy $_{j}$ & . & $\begin{array}{c}-.406 * * * \\
(.032)\end{array}$ & $\begin{array}{c}-.406 * * * \\
(.046)\end{array}$ & $\begin{array}{l}-.065 \\
(.077)\end{array}$ & $\begin{array}{c}-.252 * * * \\
(.058)\end{array}$ \\
\hline Constant & $\begin{array}{c}-.401 * * * \\
(.007)\end{array}$ & . & . & . & . \\
\hline$\sigma_{u}$ & . & . & . & . & $\begin{array}{l}2.231 \\
(.029)\end{array}$ \\
\hline$\rho$ & . & . & . & . & $\begin{array}{l}.621 \\
(.007)\end{array}$ \\
\hline$N$ & 173,708 & 103,493 & 103,493 & 36,955 & 103,493 \\
\hline
\end{tabular}

Note: Coefficients from logistic regressions. All independent variables lagged by one period. Period fixed-effects included in regressions $2-5$ (and not reported here). $* * * p<.01 ; * * p<.05 ; * p<.10$.

${ }^{1}$ In natural $\log$ form. 
Figure 1: First Differences in Predicted Probability of Directed Diplomatic Representation

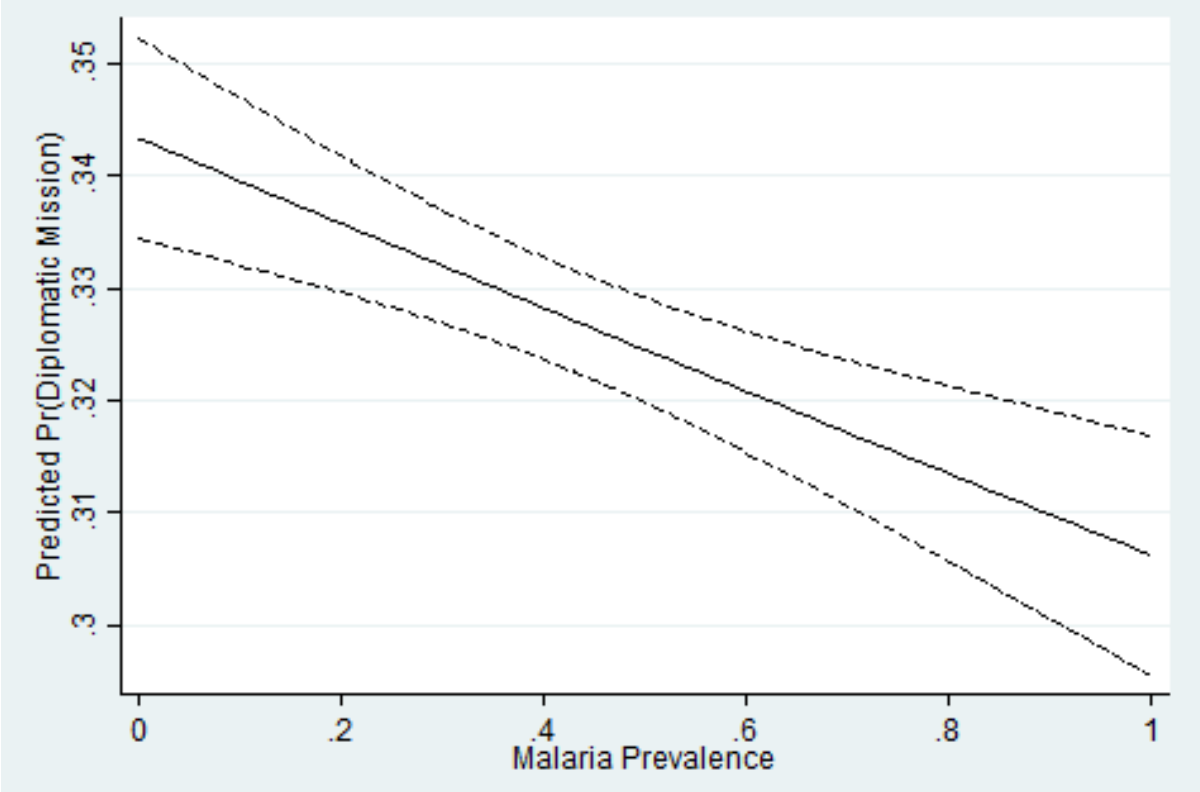

level (and independent variables lagged one year). We then estimate our five models using nonlagged versions of our independent variables. Third, we re-estimate our models using a more conservative (i.e., non-interpolated) measure of Malaria Prevelance ${ }_{j}$. Fourth, we estimate our five models using an alternative-but more temporally problematic-measure of populationbased Malaria Prevelance ${ }_{j}$ so as to show that our conclusions are generally robust to this alternate operationalization.

Fifth, to better account for sending and receiving countries' overall diplomatic popularity we construct (temporally lagged) period sums of both the total hosted diplomatic missions within host country $j$ and of the total per-period foreign diplomatic missions maintained by sending country $i$, and include these variables, along with their interactions, in their models. We then re-estimate our five specifications with the addition of controls for sending and receiving countries' educational quality — as well as the interaction of these measures-since education is an important amenity for diplomats and their families. Seventh, to account for other factors affecting the undesirability of diplomatic host countries, we add controls for each host country's ongoing levels intrastate and interstate conflict, raw CINC capabilities measures (e.g., energy consumption, urban population), and (logged) time since independence. Crucially, our 
results for Malaria Prevalence ${ }_{j}$ remain negative and-in all but one case-significant despite the reliance on all five panel specifications in each and every sensitivity analysis. This provides strong evidence as to the robustness of our dyadic findings.

\section{Country-Year Data Tests of Hypothesis 2}

\section{Data, Variables, Methods}

Given the likelihood of a given sender state $i$ establishing a diplomatic mission in host country $j$ decreases with malaria rates $(\mathrm{H} 1)$, recall that then $\mathrm{H} 2$ assumes that - by extension- the total number of diplomatic missions a host country $j$ receives will decrease as malaria rates increase. This section accordingly assesses whether Malaria Prevelance ${ }_{j}$ affects the sum total diplomatic missions that a given host country $j$ received from all other countries of the world during the same five year intervals examined above (1950-2005).

To perform this analysis, we first collapse the 1950-2005 directed dyad dataset used above to the monadic level for country $j_{j}$. In this process, a number of control variables that were specific to the sending country $i$ and several of the directed dyad specific controls must be discarded. The resultant dependent variable, $\sum$ Diplomacy $_{a t} j$, is hence a 5-year period sum that measures the total number of diplomatic missions in host country $j$. Our main explanatory variable, Malaria Prevelance ${ }_{j}$, likewise measures the average malaria rates in a given country over a given 5-year period, and is identical to the one used in the previous analysis stage.

Our controls include (i) the sum total of country ${ }_{j}$ 's trade in during a given period, Global Trade ${ }_{j}$; (ii) the percent of country $j$ located in the tropics. \% Tropics $_{j}$; (iii) average GDP per capita, $G D P p c_{j}$; (iv) host country j's average material capacities, $C I N C_{j}$; (v) country j's average distance from all other countries in the world during a given 5-year period, Remoteness $j$; and (vi) the average number of years during a given 5-year period a country was indicated as a by Cheibub, Gandhi and Vreeland (2010), Democracy. ${ }_{j}$. As above, these controls together allow us to account for important potential confounders discussed in related literatures (e.g., Sachs and Malaney, 2002; Neumayer, 2008). All independent and control variables are again lagged by one 5-year period prior to analysis, and all but the baseline models include time-period fixed effects. 
As $\sum$ Diplomacy $_{a t} j$ is a count variable and initial tests indicate a presence of overdispersion in our observed count values (see the Supplemental Appendix), we employ a negative binomial (NB) model in the analyses below. As above, we begin by reporting a negative binomial model that includes only Malaria Prevelance ${ }_{j}$ with no adjustments or controls for panel-data issues, followed by a control-inclusive (full), country-clustered standard errors, host country fixed effects, and host country random effects models. Together these models help to ensure that any Malaria Prevelance ${ }_{j}$ effects identified are not due to panel-data specific concerns, nor the assumptions we make in addressing these concerns in various manners.

\section{Results}

Table 2 report the estimates from our five NB model specifications. Across every model specification, Malaria Prevelance ${ }_{j}$ has a negative and statistically-significant $(p<.01)$ effect on the number of diplomatic missions in a given host country $j$, even after controlling for a large number of potential confounders and panel-data specific concerns. These findings confirm hypothesis $\mathrm{H} 2$, and suggest that high malaria rates can indeed deter countries from establishing diplomatic contacts. As above, the results are not due to the fact that tropical states more broadly are less likely to receive diplomatic missions. Indeed, the coefficient of \% Tropics $_{j}$ is positive and statistically significant across all models, suggesting that countries in the tropics are more likely, on average, to receive more diplomatic missions.

Additionally, increases in $G D P p c_{j}$, Global Trade ${ }_{j}$, and $C I N C_{j}$ each have a positive and statistically significant association with higher counts of diplomatic missions hosted by a country, in line with geopolitical and economic rationales for targeting a country with one's embassies. Controlling for these factors, Democracy $_{j}$ and Remoteness $_{j}$ each have a negative and statistically significant effect on the total count of hosted diplomatic missions. This is in line with Neumayer (2008), who suggests that these effects (which are not robust to the additional model specifications presented below) may arise out of the fact that aside from OECD members, democratic countries may be less attractive targets for one's diplomatic influence. ${ }^{19}$

To better evaluate the coefficient estimates in Table 2, we calculate the predicted counts

\footnotetext{
${ }^{19}$ Using Polity 2 (Marshall, Jaggers and Gurr, 2010) in place of Democracy ${ }_{j}$ yields a similar effect for democracy, and comparably robust results for Malaria Prevelance ${ }_{j}$.
} 
Table 2: Determinants of Diplomatic Representation (at Receiver), 1950-2005

\begin{tabular}{|c|c|c|c|c|c|}
\hline & Malaria-Only & Pooled & Clustered SEs & Receiver FEs & Receiver REs \\
\hline Malaria Prevelance $_{j}$ & $\begin{array}{c}.564 * * * \\
(.045)\end{array}$ & $\begin{array}{c}.160 * * * \\
(.039)\end{array}$ & $\begin{array}{c}.160^{* *} \\
(.065)\end{array}$ & $\begin{array}{c}.108^{* *} \\
(.046)\end{array}$ & $\begin{array}{c}-.119 * * * \\
(.043)\end{array}$ \\
\hline$\%$ Tropics $_{j}$ & . & $\begin{array}{c}.218 * * * \\
(.034)\end{array}$ & $\begin{array}{c}.218 * * * \\
(.073)\end{array}$ & . & $\begin{array}{c}253 * * * \\
(.057)\end{array}$ \\
\hline Global Trade $_{j}^{1}$ & . & $\begin{array}{l}.001 * * * \\
(.0001)\end{array}$ & $\begin{array}{l}.001 * * * \\
(.0001)\end{array}$ & $\begin{array}{l}.001 * * * \\
(.0001)\end{array}$ & $\begin{array}{l}.001 * * * \\
(.0001)\end{array}$ \\
\hline$G D P p c_{j}^{1}$ & • & $\begin{array}{c}.048 * * * \\
(.017)\end{array}$ & $\begin{array}{l}.048^{*} \\
(.028)\end{array}$ & $\begin{array}{l}-.059 * \\
(.035)\end{array}$ & $\begin{array}{c}.024 \\
(.024)\end{array}$ \\
\hline $\operatorname{CINC}_{j}{ }^{1}$ & . & $\begin{array}{c}.144 * * * \\
(.010)\end{array}$ & $\begin{array}{c}.144 * * * \\
(.017)\end{array}$ & $\begin{array}{c}.092 * * * \\
(.029)\end{array}$ & $\begin{array}{c}.155 * * * \\
(.013)\end{array}$ \\
\hline Democracy $_{j}$ & . & $\begin{array}{c}-.096 * * * \\
(.026)\end{array}$ & $\begin{array}{c}-.096 * * * \\
(.036)\end{array}$ & $\begin{array}{l}-.037 \\
(.030)\end{array}$ & $\begin{array}{l}-.056 \\
(.028)\end{array}$ \\
\hline Remoteness $_{j}^{1}$ & . & $\begin{array}{c}-.298 * * * \\
(.035)\end{array}$ & $\begin{array}{c}-.298 * * * \\
(.071)\end{array}$ & $\begin{array}{c}-.606 * * * \\
(.088)\end{array}$ & $\begin{array}{c}-.374 * * * \\
(.060)\end{array}$ \\
\hline Constant & $\begin{array}{c}3.989 * * * \\
(.028)\end{array}$ & . & . & . & . \\
\hline$\alpha$ & $\begin{array}{c}0.475 \\
(0.020)\end{array}$ & $\begin{array}{l}0.068 \\
(.005)\end{array}$ & $\begin{array}{l}0.068 \\
(.011)\end{array}$ & . & . \\
\hline $\ln r$ & . & . & . & . & $\begin{array}{l}3.719 \\
(.160)\end{array}$ \\
\hline $\ln s$ & . & . & . & . & $\begin{array}{l}3.858 \\
(.178)\end{array}$ \\
\hline$N$ & 1,319 & 1,072 & 1,072 & 1,053 & 1,072 \\
\hline
\end{tabular}

Note: Coefficients from negative binomial regressions. All independent variables lagged by one period. Period fixed-effects included in regressions $2-5$ (and not reported here). $* * * p<.01 ; * * p<.05 ; * p<.10$.

${ }^{1}$ In natural $\log$ form.

of $\sum$ Diplomacy $_{a t}$ across the range of Malaria Prevelance ${ }_{j}(0 \rightarrow 1)$ along with their $95 \%$ confidence intervals, holding all other variables at their means (for continuous variables) or modes (for ordinal and dichotomous ones). In keeping with our dyadic assessments, our predicted counts were calculated using the Malaria Prevelance ${ }_{j}$ estimates presented in Model 2. As Figure 2 illustrates, across the range of Malaria Prevelance ${ }_{j}$, the predicted count of $\sum$ Diplomacy $_{a t}$ j decreases from $\sim 43$ to $\sim 36$, or an average decrease of about eight diplomatic missions at host country $j$. This effect is quite substantial considering our sample size and specification choices. Comparing the results, again, to either $G D P p c_{j}$ or Remoteness ${ }_{j}$ in this case, we find that a comparable change decreases the expected count of $\sum$ Diplomacy $_{a t} j$ by 
Figure 2: First Differences in Expected Number of Received Diplomatic Missions

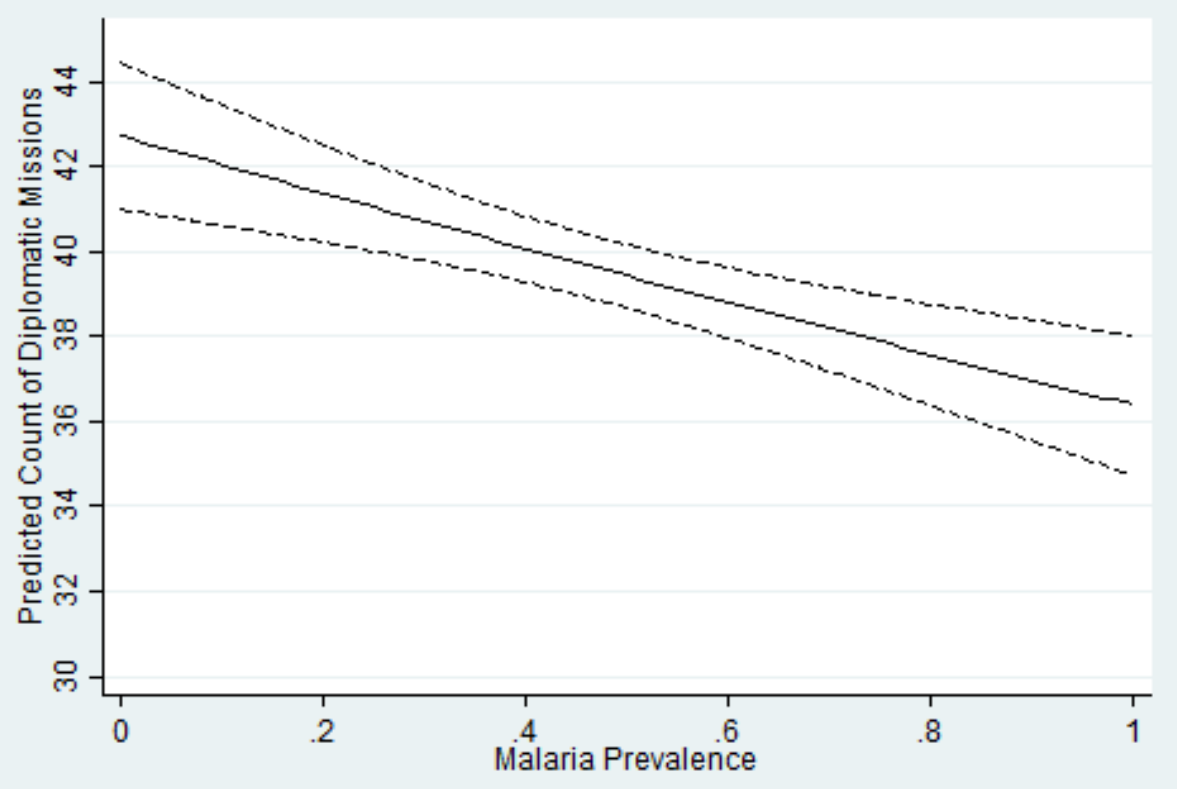

approximately two and four missions, respectively. Therefore, Malaria Prevelance ${ }_{j}$ appears to have a sizable effect on a country's total number of diplomatic missions received.

\section{Accounting for Endogeneity and Serial Correlation}

Finally, there is a possibility that the likelihood of establishing and the number of diplomatic missions in our data exhibits both serial correlations over time and endogeneity with Malaria Prevelance $j$ due to omitted confounds. Accordingly, below we employ a series of generalized method of moments (GMM) dynamic models. A key assumption of these GMM models is that the necessary instruments are "internal" and rely on lagged values of the instrumentedi.e., the dependent—variable (Arellano and Bond, 1991). To ensure that any serial correlations, e.g., due to autoregressive (AR) processes, are additionally accounted for, we rely on a special, more robust type of GMM model, called system GMM, which is the most effective at accounting for such serial correlations (Blundell and Bond, 1998). The model is specified as a system of equations, one per time period, where the instruments applicable to each equation differ because in later time periods, additional lagged values of the instruments exist. Since we are considering panel models, unit fixed effects are canceled-out, providing a straightforward 
instrumental variable estimator.

We estimate two models, corresponding to our (full) dyadic and monadic data specifications, respectively. Results are reported in Table 3. Most importantly, these models show that Malaria Prevelance ${ }_{j}$ 's effects remain statistically and substantively unchanged when accounting for these additional concerns. This means that these effects are not the result of either endogeneity or serial correlations in the establishment of diplomatic missions, and are indeed specific to pandemic - i.e., malaria—prevalence. The $R^{2}$ values of both model are relatively high, suggesting that the models provide a good fit for the data. Finally, Sargan tests are statistically significant in the dyadic model, suggesting the model is robust but weakened by the many instruments. The lack of such statistically significant Sargan test estimates in the monadic model suggest the models are robust and effectively specified. Overall, then, the GMM models lend strong additional support to both hypotheses $\mathrm{H} 1$ and $\mathrm{H} 2$ in showing that, once serial correlation and endogeneity are more fully accounted for, the results of our main analysis remain statistically and substantively unchanged.

\section{Conclusion}

If, as we find, pandemic prevalence has a notable adverse effect on the modern political ties of nation states, what are the implications? First, these findings suggest that international relations scholars should be more aware of the effect of pandemics on diplomacy and global politics more broadly. Indeed, our findings are focused on malaria and our substantive estimates were calculated using the most conservative model specifications. Our substantive findings above hence provide the most conservative estimates of pandemics' effects on diplomacy. Once one adds other pandemics - e.g., TB, ebola, and possibly even influenza and HIV—-these substantive impacts will likely increase. Future research would hence benefit not only from incorporating the role of these different pathogens into similar analyses, but also from giving such factors a more central role in theories of international relations.

This follows a line of research that associates such diseases—especially malaria—with a host of socioeconomic and political impacts, ranging from trade through tourism to conflict and stability (e.g., Sachs and Malaney, 2002; Neumayer, 2008; Peasah et al., 2013; Nicholson, 
Table 3: Determinants of Directed Diplomatic Representation, 1950-2005 (GMMs)

\begin{tabular}{|c|c|c|}
\hline & $\begin{array}{l}\text { Diplomacy }_{i \text { at } j} \\
\text { (Dyadic) }\end{array}$ & 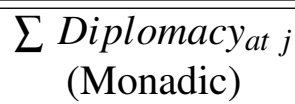 \\
\hline$\overline{\text { Malaria Prevelance }}_{j}$ & $\begin{array}{c}-0.014 * * \\
(0.006)\end{array}$ & $\begin{array}{c}-6.638 * * * \\
(2.451)\end{array}$ \\
\hline Percent Tropics $_{j}$ & $\begin{array}{c}0.057 * * * \\
(0.006)\end{array}$ & $\begin{array}{l}5.724 * * \\
(2.865)\end{array}$ \\
\hline Distance $_{i j}{ }^{1}$ & $\begin{array}{c}-0.084 * * * \\
(0.003)\end{array}$ & - \\
\hline Dyadic Trade $_{i j}{ }^{1}$ & $\begin{array}{c}0.020 * * * \\
(0.001)\end{array}$ & - \\
\hline Colonial Ties $_{i j}$ & $\begin{array}{c}0.138 * * * \\
(0.012)\end{array}$ & - \\
\hline Diplomacy $_{j}$ at $i$ & $\begin{array}{c}0.450 * * * \\
(0.005)\end{array}$ & - \\
\hline$G D P p c_{j}^{1}$ & $\begin{array}{c}0.011 * * * \\
(0.002)\end{array}$ & - \\
\hline$G D P p c_{j}^{1}$ & $\begin{array}{c}0.026 * * * \\
(0.003)\end{array}$ & $\begin{array}{l}1.136 \\
(1.215)\end{array}$ \\
\hline 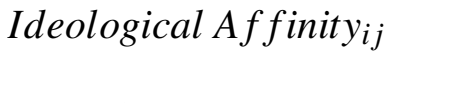 & $\begin{array}{c}-0.148 * * * \\
(0.025)\end{array}$ & - \\
\hline$C I N C_{i}^{1} \times$ Ideology & $\begin{array}{l}-0.003 \\
(0.003)\end{array}$ & - \\
\hline $\operatorname{CINC}_{j}{ }^{1} \times$ Ideology & $\begin{array}{c}-0.026 * * * \\
(0.003)\end{array}$ & - \\
\hline $\operatorname{CINC}_{i}{ }^{1}$ & $\begin{array}{c}0.047 * * * \\
(0.002)\end{array}$ & - \\
\hline $\operatorname{CINC}_{j}{ }^{1}$ & $\begin{array}{c}0.052 * * * \\
(0.002)\end{array}$ & $\begin{array}{c}7.154 * * * \\
(0.928)\end{array}$ \\
\hline Democracy $_{i} *$ Democracy $_{j}$ & $\begin{array}{c}0.028 \\
(0.007)\end{array}$ & - \\
\hline Democracy $_{i}$ & $\begin{array}{c}0.040 * * * \\
(0.005)\end{array}$ & - \\
\hline Democracy $_{j}$ & $\begin{array}{c}-0.036^{* * * *} \\
(0.005)\end{array}$ & $\begin{array}{c}0.274 \\
(1.560)\end{array}$ \\
\hline Global Trade $_{j}{ }^{1}$ & - & $\begin{array}{c}0.036 * * * \\
(0.004)\end{array}$ \\
\hline Remoteness $_{j}{ }^{1}$ & - & $\begin{array}{c}-22.345 * * * \\
(4.269)\end{array}$ \\
\hline$N$ & 185,772 & 1,991 \\
\hline$R^{2}$ & 0.563 & 0.898 \\
\hline Sargan $\chi^{2}$ & $6,858.708 * * *(\mathrm{DF}=92)$ & $97.195(\mathrm{DF}=83)$ \\
\hline
\end{tabular}

Note: Coefficients from GMM regressions. All independent variables lagged by one period. Period fixed-effects included in both models (and not reported here). $* * * p<.01 ; * * p<.05 ; * p<.10$.

${ }^{1}$ In natural log form. 
1992; Bagozzi, 2016; Enemark, 2017). Our findings add to this impressive body of research by showing that malaria - and pandemics more broadly-substantively impact international relations, and highlight their importance within global political analysis frameworks. They also suggest that investigations into how pandemics impact other types of international exchanges such as norms diffusion, electoral and human rights monitoring, and broader INGO activities, many yield additional novel and interesting results. Considering that in the future the prevalence of pandemics - caused by both known and emerging pathogens-is predicted to increase due to climate change (GPMB 2019), we believe that this research direction is especially important.

There are also policy implications. Knowing that pandemic prevalence can impact how diplomats make decisions on where and how to locate missions can assist host states by allowing them to illustrate they can provide hospitable environments despite these concerns-e.g., by providing access to special services to help diplomatic staff—and possibly attract additional funds to combat such issues. For sending countries, our findings highlight the importance of such concerns to their staff, and provide an avenues to improve service conditions by allocating more resources to addressing this relevant concern of their diplomatic corps. In helping to publicly bring forth these effects, our findings can have potentially important-albeit modestimplications to improving the conduct of global diplomacy. 


\section{References}

Addleton, Johnathan S. 2013. Mongolia and the United States: A Diplomatic History. Hong Kong: Hong Kong University Press.

Arellano, Manuel and Stephen Bond. 1991. "Some tests of specification for panel data: Monte Carlo evidence and an application to employment equations." The review of economic studies 58(2):277-297.

Bagozzi, Benjamin E. 2016. “On Malaria and the Duration of Civil War.” Journal of Conflict Resolution 60:813-839.

Bagozzi, Benjamin E. and Steven T. Landis. 2015. "The Stabilizing Effects of International Politics on Bilateral Trade Flows.” Foreign Policy Analysis 11:151-171.

Bayer, Reşat. 2006. “Diplomatic Exchange Data set, v2006.1.” http://correlatesofwar.org.

Beilenson, Laurence W. 1980. Survival and Peace in the Nuclear Age. Washington, D.C.: Regnery/Gateway.

Bennett, William J. 2006. America: the Last Best Hope (Volume I). Nashville: Thomas Nelson.

Blundell, Richard and Stephen Bond. 1998. "Initial conditions and moment restrictions in dynamic panel data models.” Journal of econometrics 87(1):115-143.

Burton, David H. 1990. Cecil Spring Rice: A Diplomat's Life. Cranbury, NJ: Associated University Presses, Inc.

Cheibub, Jose Antonio, Jennifer Gandhi and James Raymond Vreeland. 2010. "Democracy and Dictatorship Revisited.” Public Choice 143(1-2):67-101.

Congressional Record-House. 2005. "March 11 to April 6, 2005.” 151:4704.

Dorman, Andrew M. and Greg Kennedy. 2008. War \& Diplomacy: From World War I to the War on Terrorism. Dulles: Potomac Books.

Enemark, Christian. 2017. "Ebola, Disease-Control, and the Security Council: From Securitization to Securing Circulation.” Journal of Global Security Studies 2(2):137-149. 
Gallup, John L., Andrew D. Mellinger and Jeffrey D. Sachs. 2001. "Harvard Center for International Development: Malaria Datasets.” Harvard Center for International Development (CID) http://www.cid.harvard.edu/ciddata/geographydata.htm.

Gallup, John Luke and Jeffrey D. Sachs. 2001. "The Economic Burdon of Malaria." The American Journal of Tropical Medicine Hygiene 64(1):85-96.

Gendron, Robin S. 2006. Towards a Francophone Community: Canada's Relations with France and French Africa, 1945-1968. Canada: McGill-Queen's Press.

Global Preparedness Monitoring Board (GPMB). 2019. A WORLD AT RISK: Annual report on global preparedness for health emergencies. World Health Organization.

Hatchett, Richard J, Carter E Mecher and Marc Lipsitch. 2007. "Public health interventions and epidemic intensity during the 1918 influenza pandemic." Proceedings of the National Academy of Sciences 104(18):7582-7587.

Haywood, Staphanie and Patrick Majerus. 2014. "Achieving Cross-Border Consistency During a Nuclear Crisis.” Environment International 72:26-29.

Kinne, Brandon J. 2014. “Dependent Diplmacy: Signaling, Strategy, and Prestige in the Diplomatic Network." International Studies Quarterly 58(2):247-259.

Kissinger, Henry. 2011. On China. London, UK: Penguin Books.

Letendre, Kenneth, Corey L. Fincher and Randy Thornhill. 2010. "Does Infectious Disease Cause Global Variation in the Frequency of Intrastate Armed Conflict and Civil War?" Biological Reviews 85:669-683.

Marshall, Monty G., Keith Jaggers and Ted Robert Gurr. 2010. "Polity IV Project: Political Regime Characteristics and Transitions, 1800-2010.” Center for Systemic Peace.

McCullough, David. 1977. The Path Between the Seas: The Creation of the Panama Canal 1870-1914. New York, NY: Simon \& Schuster Paperbacks. 
Neumayer, Eric. 2008. "Distance, Power and Ideology: Diplomatic Representation in a World of Nation-States." Area 40(2):228-236.

Nicholson, KG. 1992. Clinical features of influenza. In Seminars in respiratory infections. Vol. 7 pp. 26-37.

Park, Daniel J, Gytis Dudas, Shirlee Wohl, Augustine Goba, Shannon LM Whitmer, Kristian G Andersen, Rachel S Sealfon, Jason T Ladner, Jeffrey R Kugelman, Christian B Matranga et al. 2015. "Ebola virus epidemiology, transmission, and evolution during seven months in Sierra Leone.” Cell 161(7):1516-1526.

Peasah, Samuel K, Eduardo Azziz-Baumgartner, Joseph Breese, Martin I Meltzer and MarcAlain Widdowson. 2013. "Influenza cost and cost-effectiveness studies globally-a review." Vaccine 31(46):5339-5348.

Rosati, Jerel and James Scott. 2010. The Politics of United States Foreign Policy. Boston: Wadsworth Cengage Learning.

Rose, Andrew K. 2007. "The Foreign Service and Foreign Trade: Embassies as Export Promotion." The World Economy 30(1):22-38.

Sachs, Jeffrey and Pia Malaney. 2002. "The Economic and Social Burden of Malaria." Nature 415:680-685.

Sawyer, Donald. 1993. "Economic and Social Consequences of Malaria in New Colonization Projects in Brazil." Social Science \& Medicine 37(9):1131-1136.

Segura-Cayuela, Rubén and Josep M. Vilarrubia. 2008. "The Effect of Foreign Service on Trade Volumes and Trade Partners.” Documentos de Trabajo No. 0808, Banco De España.

Shea, John. 1997. Macedonia and Greece: The Struggle to Define a New Balkan Nation. North Carolina: McFarland.

Singer, J. David and Melvin Small. 1973. “The Diplomatic Importance of States, 1816-1970: An Extension and Refinement of the Indicator." World Politics 25(4):577-599. 
World Health Organization (WHO). 2015. Global technical strategy for malaria 2016-2030. Technical report. 